\title{
Photographic Representation and Depiction of Temporal Extension
}

\author{
JIRI BENOVSKY \\ University of Fribourg, Switzerland
}

(Received 22 July 2010)

\begin{abstract}
The main task of this paper is to understand if and how static images like photographs can represent and/or depict temporal extension (duration). In order to do this, a detour will be necessary to understand some features of the nature of photographic representation and depiction in general. This important detour will enable us to see that photographs (can) have a narrative content, and that the skilled photographer can "tell a story" in a very clear sense, as well as control and guide the attention of the spectator of the photograph. The understanding and defence of this claim is a secondary aim of this paper, and it will then allow us to provide a good treatment of the particular case of photographic representation and depiction of temporal extension.
\end{abstract}

\section{I.}

The main task of this paper is to understand if and how photographs can represent and/or depict temporal extension (duration), given that photographs themselves are static images. In order to do this, a detour will be necessary to understand some features of the nature of photographic representation and depiction in general. This important detour will enable us to see that photographs (can) have a narrative content, and that the skilled photographer can "tell a story" in a very clear sense, as well as control and guide the attention of the spectator of the photograph. The understanding and defence of this claim is a secondary aim of this paper, one that will then allow us to provide a good treatment of the particular case of photographic representation and depiction of temporal extension.

Before embarking on this detour, let us start with some introductory questions and distinctions. How can a photograph, given that it is a static

Correspondence Address: Jiri Benovsky, Department of Philosophy, University of Fribourg, Av. de l'Europe 20, 1700 Fribourg, Switzerland. Email: jiri@benovsky.com 
image, represent temporal extension? Can it? And if it can, how long an interval is it capable of representing? According to one tradition (Harris, 1744; Lessing, 1969), static images like paintings or photographs can only represent instants - moments without duration, without temporal extent, instantaneous states of affairs - precisely because such images themselves are static. Robin Le Poidevin defends a similar thesis, while avoiding the problematic ontological commitment to instants: he claims that "static images depict ... the 'specious instant': the smallest perceivable part of an interval" (Le Poidevin, 1997, p. 188; emphasis added).

In order to evaluate these claims, we first need to make a clear distinction between photographic representation and photographic depiction, and as Le Poidevin does, we can borrow this distinction from Currie (1995). A photograph depicts what is immediately accessible to the spectator via a direct perception of the photograph, through visual resemblance. A photograph of a mountain depicts a mountain by visually resembling a mountain. But a photograph can represent a larger and richer content than what it depicts. Let us examine the two photographs below of the just-married couple (an example that will be of use later as well).

These photographs depict the couple as having such-and-such shapes, suchand-such facial expressions, as wearing such-and-such clothes, and so on, but

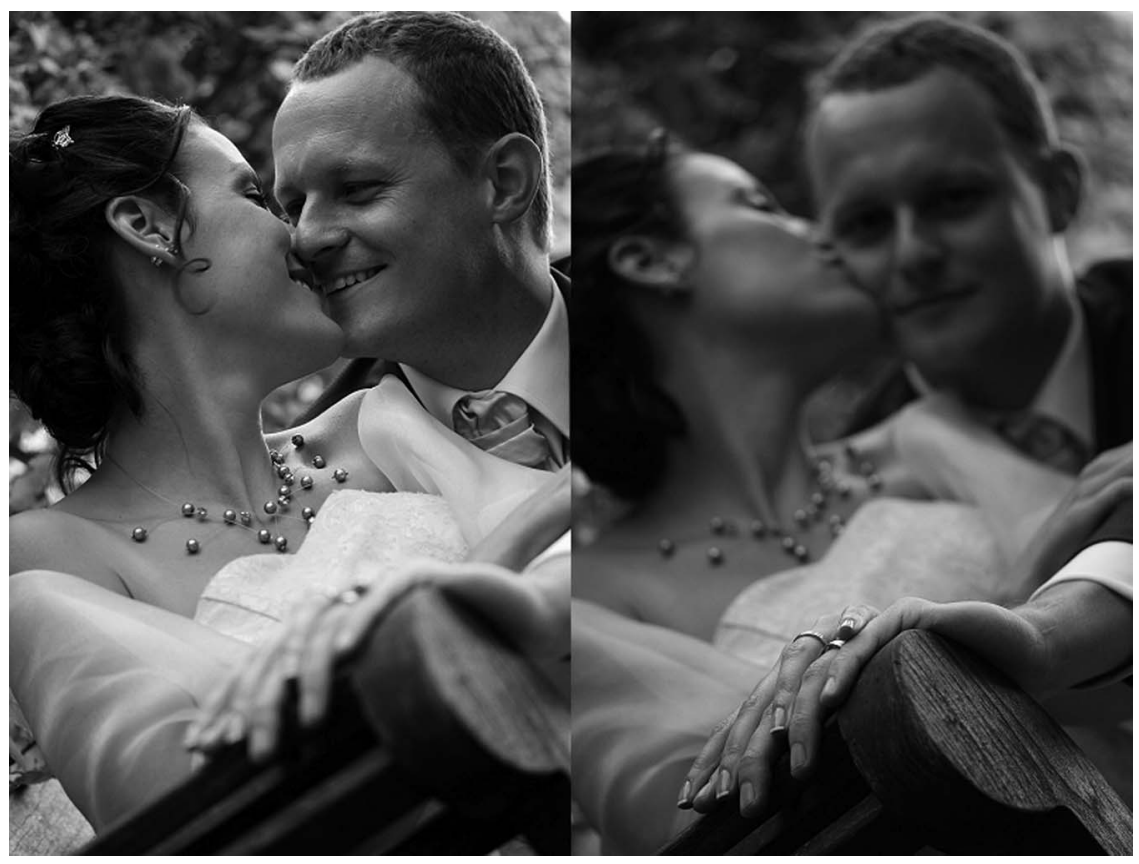


in addition to this the photographs also represent, for instance, that the couple are in love. Their being in love is not directly visually perceivable by the observer of the photograph, this fact is only represented by the photograph and it is something more than what the photograph depicts. Unlike depiction, I believe that representation is strongly linked to the narrative powers of photographs: in short, photographs depict what is directly visually accessible and they represent what they narrate, where narration strongly exploits imaginative and inferential capacities of the spectator of the photograph, as we shall see below. Prima facie, it seems then possible that photographs represent a temporal extension that is bigger than the one they depict, which parallels what Walton (2008) claims: "[Static] pictures may represent much longer sequences of events than they depict" (p. 172).

But before I advance any further on this ground, I must defend and examine in some detail the claim that photographic representation works through narration, and that the notion of photographic narration allows us thus to understand the "more" that representation can give us and depiction cannot.

\section{II.}

As Carroll (2008, Ch. 5) has convincingly argued, cinematographic narration does not work analogously to linguistic narration: "the language of cinema" can, at best, be understood as a somewhat misleading metaphor. Nevertheless, the motion picture makers can "tell a story" and communicate with the spectator in a very respectable sense. I believe that this is so in the case of static images like photographs as well: photographs (can) have narrative content in addition to being images that depict and/or represent the world. Look again at the two photographs of the married couple. Both depict almost the same objects and yet each of them tells a different story: the first one is about love and sharing of intimate feelings between the two persons, and while it of course shows that it is a wedding scene, it does not make this a central point of the story it tells, whereas the second photograph mostly insists on the idea of a wedding and lets the couple only play a secondary role.

How does narration work here? Concerning cinematographic narration, Carroll claims that it works through attention management: the motion picture maker guides and controls the spectator's attention, and exploits our natural perceptual capacities and tendencies to "force" us to perceive the reality that a movie depicts in a way the director wants us to see it, which allows her to communicate with the spectators. To do this, according to Carroll, the motion picture maker can use one of the following tools, either when shooting the movie or in post-production:

- decide the order in which one sees things,

- decide for how long one sees things,

- decide at what size (scale) one sees things. 
But what about photographs? Suppose that we accept Carroll's idea that cinematographic story-telling and communication works through attention management. How are we then going to defend this claim in the case of photographs, since, at least prima facie, only the third of the tools of the motion picture maker listed by Carroll is also available to the photographer, the first and the second being only available in the case of a cinematographic sequence that has a temporal extent that, precisely, photographs do not posses? Are there any properly photographic techniques that would allow for such static images to have narrative powers, analogous to sequences of cinematographic images? Can one static photographic image do the job of a sequence of a number of images that often directly depict actions in order to tell a story? The answer, obvious for the photographer, is: yes, of course.

In the following section, I will discuss some photographic techniques and show how they can be used to guide and control the spectators' attention, and I will thus show that, in a way that is similar to the case of cinema but with different means, photographers can communicate with the spectators of their images and tell a story with their photographs by using attention management techniques. We will also see how these techniques give rise to a temporally extended and temporally ordered experience of the photographic image, in spite of its static nature.

\section{III.}

The skilled photographer can purposefully control and guide the attention of the spectator of her photograph by deciding what she will look at first, where she will look next, and so on, thus deciding the trajectory of the spectator's look at the image and consequently the order in which she sees things. Several tools are at the photographer's disposal to achieve this aim:

- the choice of depth of field,

- the choice of exposure of the main subject in comparison to its environment,

- the choice of composition (rule of thirds, for instance),

- the choice of size/scale/magnification of the main subject.

These deliberate choices of the photographer (either when she takes the photograph, or in post-production) will allow her to create a photographic image that will be perceived in a sequenced and ordered way (first, the spectator will look at this, then she will look at that, and so on), and that also will make some of the depicted elements more salient or more perceptually important than others. Thus, when using these techniques, the photographer will create an image whose perception will be ordered and temporally extendedin a way somehow similar to a perception of a cinematographic sequence. To have a clear example in mind, let us look at the photograph of a ladybug below. 


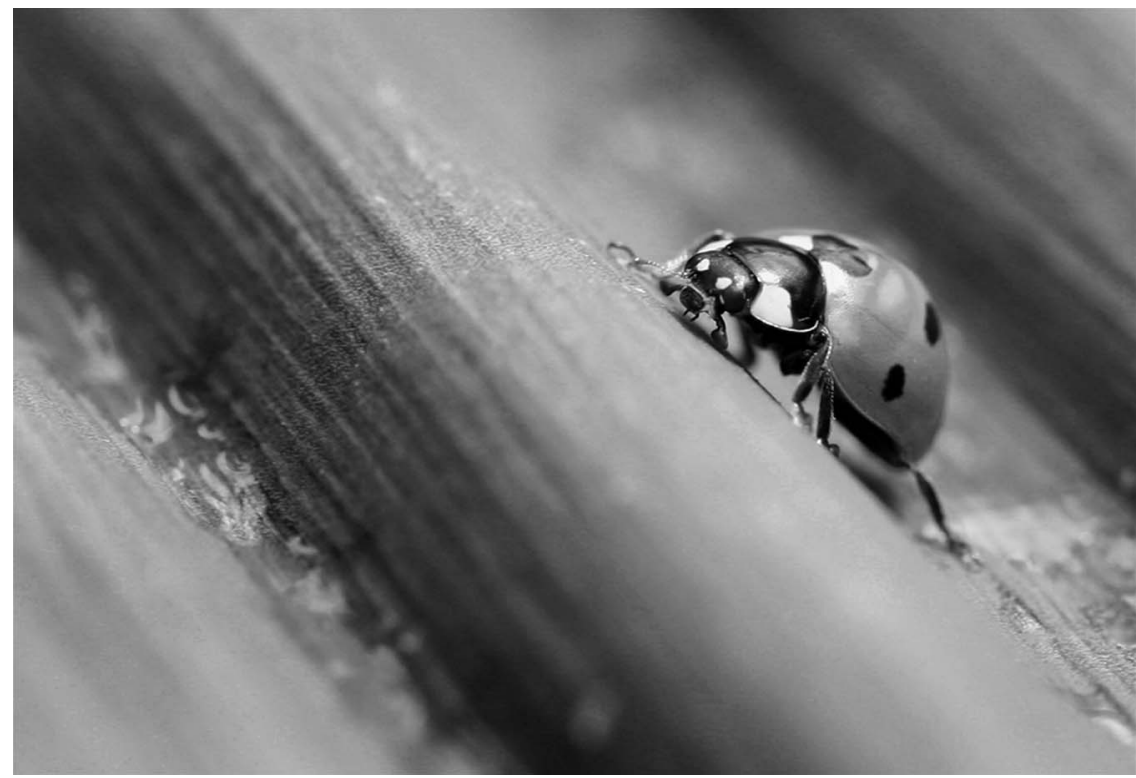

Each of the four choices mentioned above has been made here in such a way that it allows the photographer to control the spectator's attention. Let us start with depth of field (DOF). DOF is the extent of the sharp zone on the image: the "portion of reality" that is depicted on the photograph as sharp. A photographer has at her disposal several tools to control the extent of DOF as well as the amount and the quality of blur on the image (most importantly, these tools include aperture, focal length, the size of the sensor or film used, the distance between the sensor and the subject during the shot, as well as many post-production tools). In the case of the photograph of the ladybug, this sharp zone includes the ladybug itself and a part of the leaf on which it is positioned which creates here a sort of "sharp path" in the middle of a blurred leaf. The photographer thus urges the spectator not only to look at a ladybug but to follow with her look the path drawn on the leaf by a choice of a shallow DOF, which will immediately trigger the spectator's imaginative faculties and make her think of the ladybug as walking on this path. This is how the photographer creates more than just a depiction of an insect: she creates a story, a story about a ladybug that takes a walk on a leaf.

Let us follow the look of a spectator of this photograph: first, it will be attracted by the ladybug itself, then it will follow the "sharp path" on the leaf, it will then come back to the ladybug, and probably examine it more carefully. The perception of this photograph will then typically be temporally extended and ordered, where the order in which one sees things was carefully chosen by the photographer. Similarly to the motion movie maker, the photographer 
can purposefully "force" the look of the spectator of her photograph to go over the image in a pre-determined order, and thus "force" her to understand the story she wants to tell. The narrative content of the photograph would have been quite different if, for instance, the photographer had chosen a very large DOF in such a way that the whole image were sharp: without the "sharp path" drawn on the leaf, there would be no clear story of a ladybug taking a walk on a leaf.

The phenomenon that is exploited here by the photographer is the natural disposition of our perceptual system to first look at what is sharp and only then at what is blurred (probably because what is sharp provides more information). Using this natural perceptual tendency, the photographer makes the choice of a shallow DOF and thus effectively guides the spectator's attention exactly as if she said "look here!" and "look there!" When using this technique, the photographer does not really give any choice to the observer of her photograph: naturally, the perceptual system of any normal observer will make her look first at what is sharp and only then at what is blurred.

This effect is also reinforced by some of the other tools and choices mentioned above. Composition, for instance, plays a crucial role: positioning the ladybug on the image in accordance with the rule of thirds is very important here, for if the insect were positioned in the centre of the image, there wouldn't be enough space in front of it to allow the spectator to naturally imagine that she will go forward (following the "sharp path"), and take a walk on a leaf. Furthermore, positioning the ladybug in the centre of the image would create space on its right that would be empty of meaning (given the photographer's purpose here).

Combining the choice of a shallow DOF and of a composition that respects the rule of thirds, then, allows the photographer to control the spectator's attention, but also to create a static image whose perception is dynamic - as we have just seen, the look of the observer of the photograph will follow a carefully planned path on the photograph. This is important not only with respect to the narrative function of the image but also because it gives rise to a photograph whose perception mimics the way we naturally perceive objects around us. Try to look at some static object in front of you, and try to do it without moving your eyes at all; that is, focus on it, or on a part of it, and keep your look steady and rigid. Most people find such an experience uncomfortable, and some people find even very difficult to perform it. The reason is simply that our normal natural way of perceiving objects in the world around us is dynamic: very often it is just by moving our eyes, but also by moving our bodies, that we observe an object that we look at; we focus on some parts of it first, on other parts then, we examine it, our look goes over it. A photograph that allows ("forces") the spectator to have her look go over and examine the image in a similar dynamic way will allow for a perception of it that is more natural and more like normal visual perception than a photograph that would force the look of the observer to remain fixed on one part of the image - this would happen, for instance, if the photographer had chosen to ignore the rule 
of thirds and had created an image with the ladybug positioned in the centre of the image.

In addition to composition and DOF, the choice of exposure and size of the main subject play an important role when it comes to controlling and guiding the attention of the spectator of a photograph. Indeed, exactly as our perceptual apparatus makes us first look at what is sharp and then at what is blurred, it also makes us typically first look at what is bright and big. The latter is really quite obvious: if the main subject occupies a big portion of the whole image, and even more if it is magnified like in the case of the macrophotograph of the ladybug, it will be natural for the observer to look at it in the first place, and only then visually explore other parts of the image - thus, the main subject comes first in the perceptual sequence of the photograph. As before, the look of the observer of the photograph is here "forced" to do so, and it would be practically impossible for a normal human observer not to look at the ladybug first when perceiving the photograph (at least, when perceiving it for the first time).

Correct exposure of the photograph, then, completes this function in an important way. Indeed, any bright zones on the image will attract the observer's attention, exactly as is the case for sharp zones. Of course, it is possible for the main subject to be darker than the background and still be perceived first by the observer, but if, for instance, there are any over-exposed very bright ("burned") zones on the image, an observer will have the tendency to be visually attracted by them and thus to be distracted from the main subject. Thus, correct exposure of the main subject and of the background is crucial when it comes to reinforcing the order of the perceptual sequence that the photographer has decided for the observer to follow.

To sum up, here are the claims - that parallel Carroll's claims concerning cinema - that I want to put forward:

- photographs (can) have a narrative function, they can "tell a story",

- this narrative function is not accomplished analogously to linguistic narration, but rather through attention management techniques, mostly techniques that control and guide the observer's look when she sees the photograph,

- these techniques give rise to a perception of the image that is dynamic, sequential, and temporally extended,

- these techniques seem to exploit our natural perceptual faculties that are innate rather than some learned capacities.

IV.

We have already seen that photographs depict what is directly visually accessible on the image and I now suggested that they represent what they narrate. To this distinction made by Currie and used by Le Poidevin, I would like 
to add a third term: refer to. In short, a photograph pictorially refers to the entities it depicts or represents. The photograph of the ladybug, for instance, depicts a spatial part of it (i.e., the visible spatial part of the insect's shell) while it represents it as taking a walk on the leaf, but it also makes reference to the ladybug. Reference differs from depiction because only a part, the visible part, of the subject is depicted, while the photograph refers to the whole entity (including its back side). Reference differs from representation because the photograph does not refer to the fact that the ladybug is taking a walk on the leaf - it only refers to what it visually points to, what we have here is a case of pictorial ostension. Photographs thus refer to more than what they depict, but to less than what they represent.

Now that we are armed with these distinctions, and with a proper understanding of the way photographs represent via narration, we can try to answer the question whether a static image such as a photograph can depict/ represent/refer to temporal extension. A first very important piece of answer consists in acknowledging the fact that one can only depict/represent/refer to temporal extension by depicting/representing/referring to change (typically, movement). This is not something specific to photography and not even to static images in general, since any measure of time, be it an ordinary measure or a scientific one, involves measuring change: we only measure temporal extension by observing changes - the movement of a hand on a wristwatch, the apparent movement of the sun in the sky, the succession of our own internal mental states, or a disintegration of Caesium atoms in an atomic clock. Without observation of changes, there is neither measure of elapsed time, nor ordinary perception of the passage of time. From this claim there is only one step towards the Aristotelian claim that time itself implies change, and that without change there is no time (contra Shoemaker's argument involving global temporal "freezes" of a possible world, cf. Shoemaker, 1969), or even to the stronger Leibnizian idea, defended by relationists, that time is change (i.e. for instance that time is a logical construction of events; see Forbes, 1993).

We can leave these strong metaphysical theses about the nature of time aside, but we must acknowledge that asking the question whether (and if so, how) a photograph can depict/represent/refer to temporal extension (duration) is asking the question whether (and if so, how) a photograph can depict/ represent/refer to change and movement. As we shall see, it is not difficult to realize that a photograph can represent change and temporal extension, but it is less obvious to affirm that a photograph can depict change, and so it is the latter claim that I will be most interested in. I shall start by distinguishing four ways in which one could think that a photograph can depict temporal extension (duration).

A first possible way is to make a comparison with cinema. A cinematographic work typically manages to depict temporal extension since "film can represent time by time" (Le Poidevin, 2007, p. 134); that is, given that a film is not a static image and that the cinematographic image itself is changing and 
moving, it can depict change by change and movement by movement. Clearly, photographs cannot depict change or duration in this way, which is something that not only Le Poidevin $(1997,2007)$ insists upon, but Walton as well when he says that whether static images depict movement or a static state of affairs does not depend on what happens to the image through time but on features of the image that are all present at a given moment (2008, p. 163). Indeed, a print of a photograph can change with time, as most material objects do; for instance its colours can fade out, and consequently at a given time visually perceivable features of the image are not the same as at an earlier instant, but of course this plays no role in the way a photograph could depict duration of change through time.

Let us then try another way in which a photograph can perhaps depict change and temporal extension. As we have seen above, perception of a photograph can, and often is, dynamic and temporally extended: it takes time to wholly perceive it. Thus, even if the image itself is static, our perception of it is almost always non-static and non-instantaneous. As we have seen, our perception of a photograph is very often sequential: the photographer guides our attention in such a way that we look first at this, then at that, in an order that is pre-determined (by the photographer), and in this sense even when observing an image that is static our experience of it is temporally extended and involves change through time. Can one make a comparison with our experience of cinema? Indeed, in the case of cinema, we have an experience of movement by having an experience of a rapid sequence of static images - we also see first this, and then that. But the sequence is here a temporal sequence whereas in the case of a dynamic perception of a photograph temporal order is given by spatial order - we see first this and then that because our look is first directed here and then there. The analogy between our temporally extended experience of a photograph and a temporally extended experience of film is thus only superficial, since the two cases do not work in the same way. A photograph can here be said to represent movement, change and temporal extension, but not to depict it: it represents it by "narrating" it, as we have seen in the case of the photograph of the ladybug. What we learn here is that a photograph can represent temporal extension via its narrative function but that it cannot depict it in this way since no change or movement is visually directly accessible to the observer of the image. Contra Lessing, who defended the view that painting and photography are not "temporal arts" and cannot represent more than instants (1969, p. 91-92), we see here that (and how-through narrative means) photographs can represent change, movement, and duration. Represent, yes, but not depict.

But perhaps a third possible way for photographs to depict change and duration, close to the one we have just examined, can be illustrated by the following photograph of a skier going down a slope.

The impression one gets when looking at this photograph is one of speed and movement: we can probably say that this photograph is a paradigmatic 


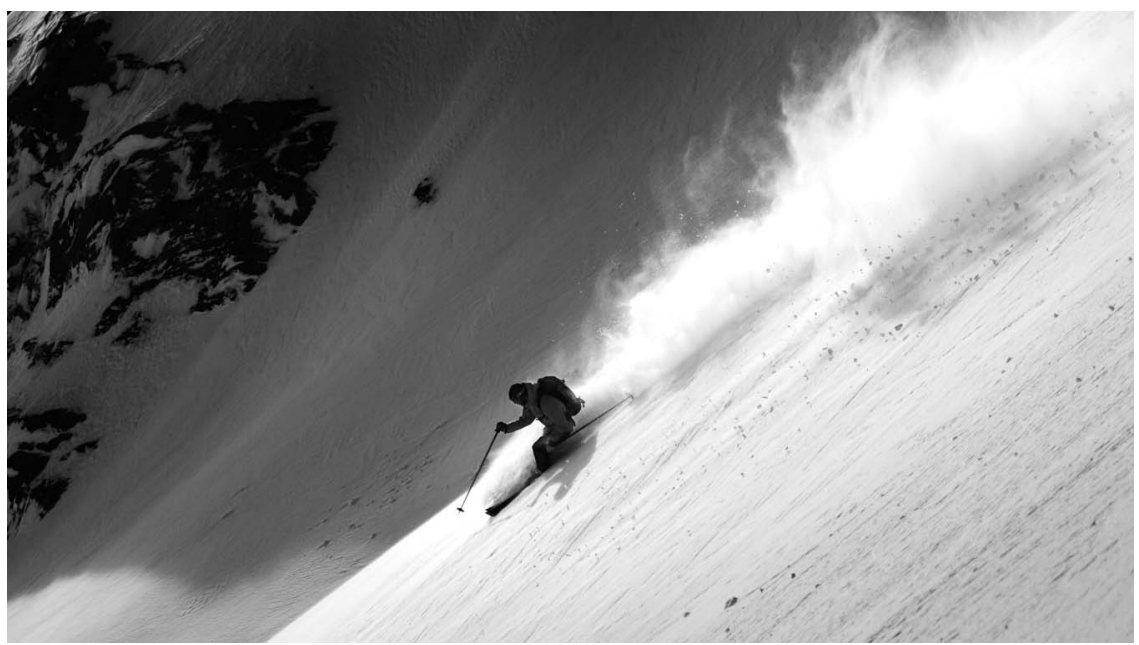

case of a photograph of a movement. But that's not the question. The question I am concerned with here is whether this photograph depicts movement or whether it only represents it. In agreement with Walton (2008) who suggests that our imagination plays a crucial role when we perceive photographs of this kind, I think that we easily see that such an image represents movement (it tells us a story about movement by triggering our imaginative capacities that make us "continue" the skier's next movements) but does not depict it - we do not directly see movement, even if it is impossible for us not to think about the skier's movement when we perceive such a photograph.

Thus, none of the photographs we have seen until now (the married couple, the ladybug, the skier) depicts movement or change, but they all represent it. Here is a fourth case that requires careful consideration, a photograph of a man who is standing up from a bench at a train station while a train passes by.

The very words in which I just described this photograph suggest movement and change: I am talking about a man who is standing up (and so, who is changing his position) and about a train that passes by (and so, that is changing its spatio-temporal location). A photograph of this kind is special in the sense that, unlike the photograph of the skier, it makes us plainly see the trajectory of these two objects across space-time during a non-instantaneous interval of time. Such an image makes us realise a trivial fact about photography that is sometimes left aside: any photograph records what takes place during a non-instantaneous interval of time, simply because taking a photograph takes time, even if most often it is very short. The photograph of the skier was taken at a shutter speed of 1/4000 second, the one of the 


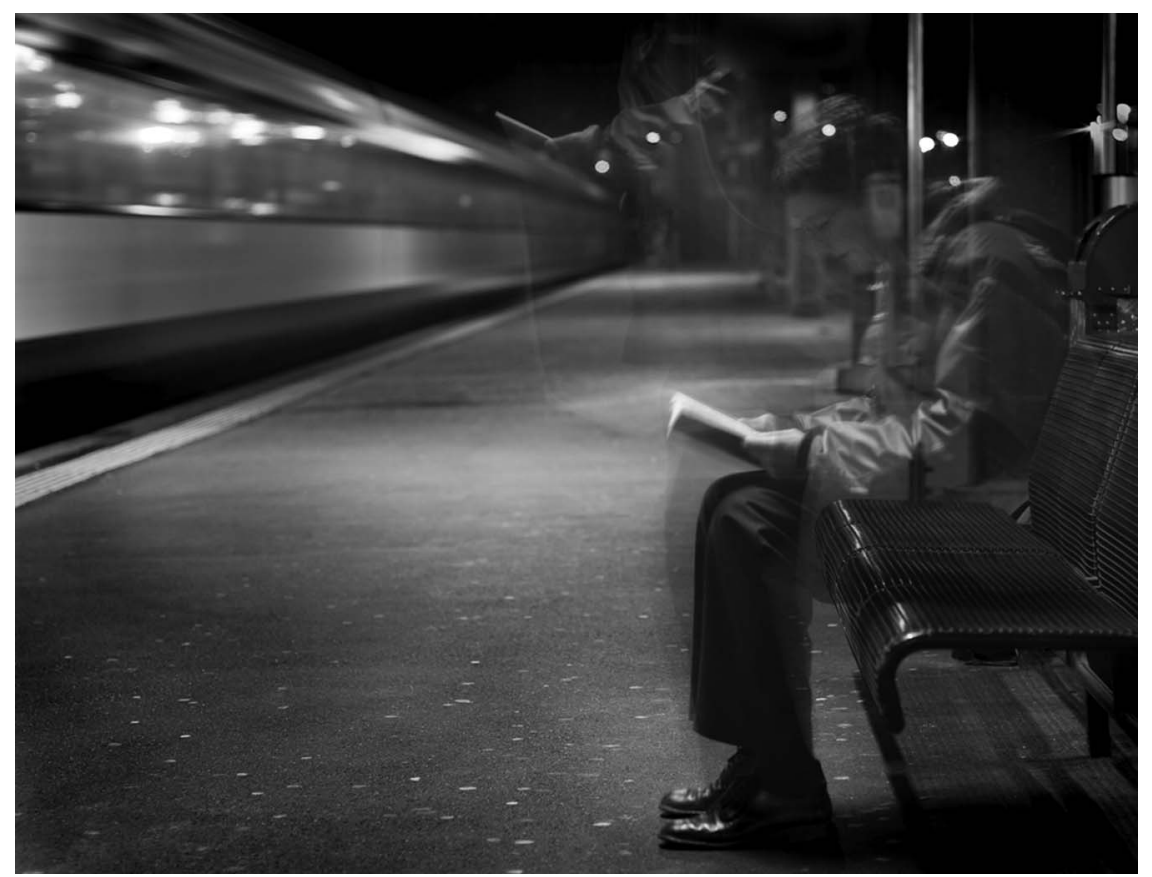

ladybug at $1 / 100$ and the one of the man at the train station at two seconds. Thus, there is no principled difference between these three photographs on this point, but of course there is an important difference with respect to what we see on the resulting images: in the case of the married couple, the ladybug or the skier we see reality as "frozen" because either the exposure time is too short (as in the case of the skier) or the movements of the subject are too slow (as in the case of the ladybug or the married couple) for them to be recorded and visually perceivable on the photograph. In the case of the photograph of the man at the train station, however, the exposure time is long enough to allow for the man's and the train's movements to be recorded on the image, where their spatio-temporal path (movement) is thus visually accessible.

Before answering the question whether such a photograph depicts change and movement (as I just seem to have suggested) or whether it only represents it (as in the previous cases we have seen above), I shall now take a "metaphysical detour" in order to better understand the nature of change, which will help us then to see whether or not change is depicted by this kind of photograph.

Indeed, the photograph of the man at the train station seems to suggest a perdurantist ${ }^{1}$ ontology and conception of change. According to perdurantism, material objects like human bodies or trains are extended in the three 
spatial dimensions but also, literally, they are extended in time. Contrary to endurantists who claim that material objects persist through time by existing entirely at different moments of time, perdurantists defend the view that material objects persist through time by having temporal parts at different moments of time. Let us use as an example the case of the man at the train station. He is not, according to perdurantism, an entity that exists first at a time $t_{1}$ (say, when he was sitting and reading on the bench) and then at a later time $\mathrm{t}_{2}$ (say, when he was starting to stand up) and again at a later time $\mathrm{t}_{3}$ (say, when he was fully standing), since he is an entity that is temporally too big (too extended) to be able to exist entirely at one time. The man is rather a "space-time worm" that is extended from $t_{1}$ to $t_{3}$ (in our example) and that has temporal parts between these two moments of which he is composed. This is analogous to the way the man occupies space: he has a left hand, a right hand, a left and a right leg, and so on, and all these spatial parts make up a whole - his body - that is extended in the three dimensions of space. Perdurantists, then, take seriously the idea that the case of temporal extension is analogous to the case of spatial extension.

It is not my purpose here to discuss in detail the perdurantist view, let alone to defend it. What I am interested in now is the very natural way in which perdurantism seems to accommodate the depictum of the photograph of the man at the train station. Somewhere between the birth and the death of the man there is, according to perdurantism, a non-instantaneous temporal part of him whose "temporal thickness" (temporal extent) is two seconds long and is extended from $t_{1}$ to $t_{3}$, and this temporal part is what the photograph depicts. One smaller temporal sub-part of this temporal part of the man is sitting, followed by another temporal sub-part that is standing up, and so on, and the $t_{1}-t_{3}$ collection of these temporal parts makes up the whole $t_{1}-t_{3}$ temporal part of the man that is the depictum of the photograph. More exactly, what we directly see on the photograph are the traces left by this temporal part on the image, due to a long exposure time. These traces are less sharp than what we could have seen were we present there and were we observing the man, since a photograph is a static medium and is not capable, contrarily to cinema, to depict movement by movement and change by change, but, in its own way, it does depict this non-instantaneous $t_{1}-t_{3}$ temporal part of the man (and the train).

But, even if we accept this idea that a photograph can depict (and not just represent) non-instantaneous temporal parts, is it true that it depicts movement and change? Indeed, nothing changes on the image (it is a static image), and it is not obvious that such a depiction is a depiction of change and movement.

I believe that the photograph does depict movement and change, and thus depicts temporal extent and duration. To see this, let us examine more closely the account perdurantism provides of the nature of change. The best way to 
understand this account is to consider an often-raised objection against perdurantism that tries to show that, precisely, perdurantism cannot account for genuine change. Indeed, according to perdurantism, the universe is a static one: everything "just sits there", the universe is a four-dimensional manifold, a distribution of matter across four-dimensional space-time that contains everything (including the past, the present, and the future) and where everything "has its place" (occupies its spatio-temporal location) for ever. Consider the case of the man at the train station: at $t_{1}$ there exists a temporal part of him that is sitting, at $t_{3}$ there exists a temporal part of him that is standing. This never changes. Once the man is sitting at $t_{1}$, it is eternally true that he is sitting at $t_{1}$ - that he has a sitting temporal part at $t_{1}$. Where is change then in this perdurantist scenario? What changes? Let us look at the man himself in his entirety. He is not identical to any of his temporal parts because he is temporally too big: he is the whole, temporally extended, composed of all of his temporal parts from his birth to his death. Does he change? According to the objector, he does not: such a temporally extended entity just is there with all of its temporal parts that never change. Thus, some will say, following, among others, Peter Simons that the "four-dimensional [i.e., perdurantist] alternative is not an explanation of change but an elimination of it, since nothing survives the change which has the contrary properties" (Simons, 2000b, p. 64). We want to give an account of how a single object, a man or a train, can persist through change and the perdurantist, according to Simons, is telling us a story about different objects (different temporal parts) having different properties (sitting, standing), but this is not the story we wanted to be told. Once it is true that a certain temporal part of the man is sitting, it will always be true - this is a fact that, according to perdurantism, cannot change. And that's what leads some to call perdurantism a "static" ontology: everything seems to be just there and no concrete particular can ever genuinely change.

In Benovsky (2006, Ch. 3), I have shown that if this were a good objection it would apply to endurantism as well as to perdurantism and consequently would not constitute a strong argument against perdurantism. But this is not where my interest now lies: let us rather see now why this is not a good objection (neither against perdurantism, nor endurantism).

What is intrinsic change? According to Judith Jarvis Thomson, "a thing changes iff it has a feature at an earlier time which it lacks at a later time" (1983, p. 210-11). Berit Brogaard claims that "change takes place when a single entity has two incompatible states at different times" (2000, p. 341). Both views follow the traditional view of Bertrand Russell that "change is the difference, in respect of truth and falsehood, between a proposition concerning an entity at a time $t$ and a proposition concerning the same entity at another time $t$ ', provided that the two propositions differ only by the fact that $t$ occurs in the one where t' occurs in the other" (Russell, 1903, \$422). What the three views have in common is that change is the having of different properties at different times. 
But if this is correct, perdurantism has nothing to fear as far as the objection above is concerned. According to perdurantism, the man who is a temporally extended four-dimensional entity has at $t_{1}$ the property of sitting and at $t_{3}$ the property of standing (by having a $t_{1}$ sitting temporal part and a $t_{3}$ standing temporal part); thus he has a property at $t_{1}$ that he does not have at $t_{3}$-and that's all that is required to be able to affirm that a change took place. Of course, an instantaneous temporal part of the man cannot change (since, as we have seen above, it will always be the case that the $t_{3}$ temporal part of the man is standing), but the man (who is not identical to such temporal parts) changes, and this is what we wanted to account for-the man, and the train, are four-dimensional entities that can possess different properties at different times, in virtue of having different temporal parts at different times, and thus can change.

The unsatisfied objector will typically try to put her "no-change objection" in a different light and claim that perdurantism takes change to be too much like spatial variation. Yes I do, a four-dimensionalist would reply, but why is this an objection to my view? Indeed, it is part of my view that time is spacelike and that material objects are extended in time just as they are in space. As Sider puts it, "the objections may simply be met head-on. Change is analogous to spatial variation. . . There are no good arguments to the contrary" (2001, p. 214). A typical perdurantist claim concerning this analogy is that an object's carrier through time is like a road's extension across space. An illuminating explanation can be found in Heller: he suggests that "we do in fact sometimes describe an object as changing in virtue of its having different properties at different places" (1992, p. 703). When I give instructions to a friend for him to find my house, to take Heller's example, I can tell him: "It's exactly two miles after the road changes from paved to dirt" and, so, I am speaking about the road as if it changed, while, in fact, I am speaking about dissimilarity of its spatial parts. If I were viewing the road from a bird's eye view (from a helicopter, for instance) I would not describe it as changing. The difference between the two cases, as Heller points out, is that in the latter I have a neutral perspective while in the former I have given my friend a direction: following this direction, the road is first paved and then dirt, and this is why I said it changed. The difference between the spatial case and the temporal case consists, then, in the fact that it seems that it is a physical fact that time, but not space, has a direction, and this is why in the temporal case, but not in the spatial case, the fact that an object possesses different properties at different times constitutes genuine change, while the fact that an object possesses different properties at different places does not (although it can seem to be one from some perspectives, as we have seen in the case of the road).

When observing the photograph of the man at the train station, we have a sort of "helicopter-like" perspective on the space-time trajectory of the man and the train. This photograph, thanks to the fact that it can record 
traces of the spatio-temporal careers of these two objects longer than those we are normally given by our ordinary perception, provides us with a visual experience of a temporal part whose temporal thickness is two seconds, and makes us see the different temporal sub-parts of this temporal part with their respective properties (sitting, standing). We can thus observe this twoseconds-long space-time worm, we can observe the qualitative differences between its temporal sub-parts, and consequently, we can observe the change that this worm underwent - thus, we see the man and the train changing. Therefore, it seems correct to me to claim that such a photograph depicts change, and temporal extent.

\section{V.}

We have seen four ways in which one could ask whether a photograph depicts change and temporal extent or whether it only represents it, and we have seen that only the fourth one seems to be a case of genuine depiction. (In this last case, the photograph also refers to the entities it depicts-for instance, it refers to the space-time worm who is the man at the train station.) It is an interesting fact that the temporal extent of the entity that is depicted by the photograph, namely the two-seconds-long space-time worm of the man, corresponds to the length of exposure time used by the photographer when she took the photograph. This gives rise to an interesting question. Let us consider the following photograph of the Matterhorn.

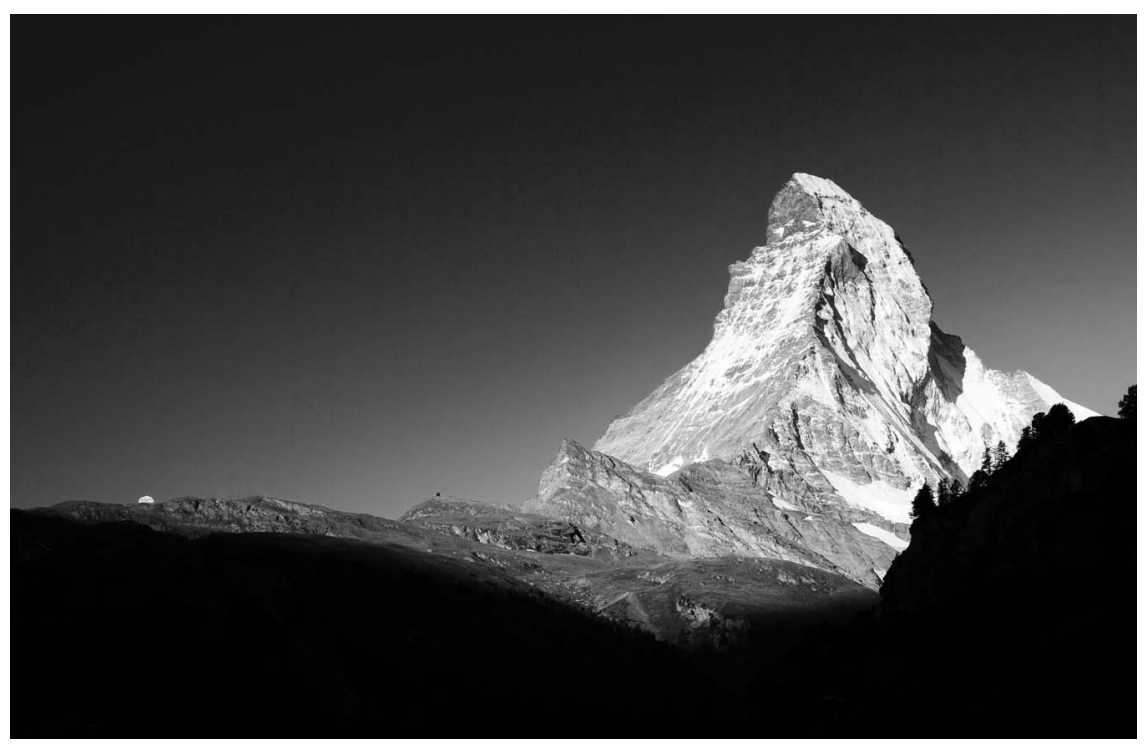


This photograph, like the one of the man at the train station, was taken at a slow shutter speed (about 1.5 seconds). The photograph of the man at the train station depicts temporal extent by depicting a two-seconds-long temporal part of the man thanks to the fact that the exposure time was two seconds. Shall we then generalize and say that if a photograph is taken at a slow shutter speed, it depicts temporal extent? The Matterhorn photograph clearly seems to suggest the contrary: it was taken at a slow shutter speed, but it does not depict temporal extent. The reason why this rule ("slow shutter speed implies depiction of temporal extent") cannot be generalized is simple: duration, and temporal extent can only be depicted via depiction of change (typically, movement). Without change, there can be no depiction of duration, because for a duration to be visually accessible to the observer of the photograph it is necessary for the depicta to undergo an observable change during the interval that corresponds to the exposure time of the shot. Without this, as it is the case for the photograph of the Matterhorn, no change will be observable on the resulting image and no duration will be depicted by such a photograph. Thus, it would be false to affirm that a photograph taken at a slow shutter speed depicts duration just in virtue of that. But the case of the Matterhorn photograph is not a counter-example to the claim that a photograph taken at a slow shutter speed of a visibly changing subject depicts duration. Indeed, it is enough to realize that observable change is a necessary condition for depiction of temporal extent.

This is not specific to photographs, as I already mentioned at the beginning of this paper. Our ordinary experience of duration is also one of change: it is only through experience of change (change in the observed entity or change in our own mental states) that we experience duration, temporal extent, the passage of time, and so on. Furthermore, as we have already seen, the aesthetic claim (about photographic depiction of duration via depiction of change) and the epistemic claim (about perception of duration via perception of change) interestingly parallel a metaphysical claim: the relationist view that time is change, or its weaker Aristotelian variant that time implies change (in both cases, without change there would be no time). The Matterhorn photograph is thus not only not a counter-example to my claim that photographs of a certain kind (i.e., like the one of the man at the train station) can depict temporal extent, but it even helps us to better understand how such a depiction works and how this aesthetic claim mirrors the epistemic and metaphysical corresponding claims. I am borrowing here a formulation from Le Poidevin (2007, p. 125) where he says that the aesthetic thesis he examines is a mirror of a metaphysical one - but, one can ask, what is exactly the nature of the link between these different theses (aesthetic, epistemic, metaphysical)? In particular, should we accept a perdurantist ontology if we accept the view that (some) photographs depict and refer to non-instantaneous temporally extended spatio-temporal parts? Following the general methodology adopted 
in Le Poidevin (2007) would seem to lead us there since he, for his part, examines the claim whether photographs can or cannot depict instants, and in a strongly parallel way devotes a big part of his article to the understanding of the nature of an instant. For Gombrich (1964) things also seem to be connected - for it is precisely because he believes that the (metaphysical) notion of an instant is absurd that he then defends the claim that photographs cannot depict (nor represent or refer to) it, since it doesn't exist. And it is precisely to avoid metaphysical troubles arising from the notion of an instant that Le Poidevin introduces the notion of a "specious instant" and claims that this is what static images like photographs depict. The specious instant, for Le Poidevin, is something that is "psychologically instantaneous" (2007, p. 138) which does not mean "instantaneous". (This is analogous to the notion of "specious present" in the literature about perception of time.) Thus, the specious instant is defined by reference to what we perceive and this is how Le Poidevin avoids that his aesthetic thesis (about depiction of specious instants by static images) presupposes a particular theory concerning the metaphysical debate about the nature of instants. But nevertheless he seems to affirm something very close to the thesis I have been defending above: "In the experience of any change we may identify a particularly salient point, such as the moment a long-distance runner crosses the finishing line. We might represent this as a time-slice of the action, but in fact (since we perceived it) it has a non-zero duration. This, then, is what static images are capable of depicting: specious instants which are parts of a larger movement represented by the image. Images can thus represent a movement by depicting perceptually minimum parts of it" (Le Poidevin, 1997, p. 186).

But, these "perceptually minimum parts" are non-instantaneous temporal parts, and it seems then that we cannot avoid providing some metaphysical account of what these are, especially if we not only say that photographs depict them but also that they pictorially refer to them.

Thus, both Gombrich and Le Poidevin take seriously the link between the aesthetic, the epistemic and the metaphysical debates, and, I believe, this is a good methodology since as we have just seen, if one claims that photographs depict a kind of entity E, it seems reasonable to ask for a metaphysical account of the nature of $\mathrm{E}$. This account can then be a fictionalist one, or a reductionist (eliminativist) one, or one that claims genuine existence of the depicta at hand-but whatever this account is, there should be one. As I have suggested above, when it comes to the depicta of photographs like the one of the man at the train station, the perdurantist account seems to be the right one. This kind of perdurantism is composed of two main claims: (i) the central perdurantist thesis that material objects persist through time by having temporal parts at different times, and (ii) the eternalist thesis according to which the past, the present and the future possess the same ontological status (i.e. the universe is a four-dimensional manifold and all of its spatial and 
temporal parts exist in the same way). The latter thesis played an important part in what I claimed above since if we say that a photograph depicts and refers to a temporal part whose "temporal thickness" is several seconds, and if we want to then affirm the genuine existence of such a temporal part, we must accept the existence of entities that are temporally "too big" to exist at only one moment - in particular at the present moment - since whatever the length of "the present time" is, it is less than several seconds. Berit Brogaard (2000) defends the view that perdurantism is compatible with the idea that only one - present - time exists, but such a claim would imply that there exist entities (space-time worms) that possess parts that don't exist - they would be composed of parts that exist (the present ones) and of parts that don't exist (the past and future ones). But such a claim, if not wholly absurd, at least generates a series of troubles that one would do better to avoid. ${ }^{2}$ It is thus more adequate, and clearly more natural and simpler, to provide an account of the depicta of photographs such as the one of the man at the train station in terms of an eternalist version of perdurantism (or, an equivalent version of endurantism). ${ }^{3}$ When looking at this photograph we see a worm that extends over the image that depicts and refers to a space-time perdurantist eternalist worm, and it seems then indeed that, to borrow again Le Poidevin's formulation, that aesthetics is here the mirror of metaphysics. Instead of taking this to be a cumbersome drawback of the aesthetic thesis, I suggest to interpret this strong link between aesthetics and metaphysics as the good news that different fields of philosophy join together in order to provide us with a unified and complete account. ${ }^{4}$

\section{Notes}

1. There are various versions of perdurantism defended for instance by Mark Heller (1990, 1992, 1993, 2000), Robin Le Poidevin (2000), David Lewis (1983, 1986, 1988, 2002), W. V. O. Quine (1950), and Ted Sider (1997, 1999, 2000a, 2000b, 2001); objectors include Peter Simons (2000a, 2000b), D. H. Mellor (1998), and Peter Van Inwagen (1981, 1990, 1985, 2000). I shall here discuss only one of these versions: "the worm view". It is not necessary for my present purposes to go into the details of the other variants. For a detailed discussion of all variants of perdurantism and endurantism the reader can consult Benovsky (2006, 2009a, 2009b).

2. See Benovsky (2009a) for a detailed discussion.

3. Alternatively, one could want to try to accommodate the depicta of photographs like the one of the man at the train station using an endurantist eternalist ontology. In Benovsky (2009b), I carefully explore the similarities and differences between the eternalist versions of endurantism and perdurantism, and I conclude that there is actually much less of a difference between the two views than what is usually thought (again, and only, when both work under the eternalist hypothesis) - not just with respect to the case of depicta of photographs but with respect to other traditional metaphysical puzzle cases. Under this hypothesis (see especially Section 2.3 of Benovsky, 2009b), and while the perdurantist picture seems a bit more natural and comfortable, both views can indeed accommodate the case of the depicta of photographs taken with a long exposure time. This claim (of equivalence between endurantism and perdurantism) requires careful argumentation, and I have 


\section{Jiri Benovsky}

no space to discuss it here, this is why, somewhat frustratingly, I must simply refer to my paper (Benovsky, 2009b).

4. All photographs used as illustrations in this paper are under copyright by Jiri Benovsky (www.benovsky.com).

\section{References}

Benovsky, J. (2006) Persistence through time and across possible worlds (Ontos Verlag).

Benovsky, J. (2009a) "Presentism and persistence", Pacific Philosophical Quarterly, 90(3), pp. 291-309.

Benovsky, J. (2009b) "Eternalist theories of persistence through time: Where the differences really lie", Axiomathes, 19(1), pp. 51-71.

Brogaard, B. (2000) "Presentist four-dimensionalism", The Monist, 83, pp. 341-54.

Carroll, N. (2008) The Philosophy of Motion Pictures (Malden: Blackwell Publishing).

Currie, G. (1995) Image and Mind: Film, Philosophy and Cognitive Science (Cambridge: Cambridge University Press).

Forbes, G. (1993) "Time, events, and modality", in: R. Le Poidevin and M. MacBeath (Eds.) (1993), pp. 80-95.

Gombrich, E. (1964) "Moment and movement in art", Journal of the Warburg and Courtauld Institutes, 27, pp. 293-306.

Harris, J. (1744) "Three treatises concerning art", in: E. Lippman (Ed.) Musical Aesthetics: A Historical Reader (Glamorgan: Pendragon Press, 1988).

Heller, M. (1990) The Ontology of Physical Objects: Four-dimensional Hunks of Matter (Cambridge: Cambridge University Press).

Heller, M. (1992) "Things change", Philosophy and Phenomenological Research, 52, pp. 695-704.

Heller, M. (1993) "Varieties of four-dimensionalism", Australasian Journal of Philosophy, 71, pp. $47-59$.

Heller, M. (2000) "Temporal overlap is not coincidence", The Monist, 83, pp. 362-80.

Le Poidevin, R. (1997) "Time and the static image", Philosophy, 72(280), pp. 175-88.

Le Poidevin, R. (1990) "Relationism and temporal topology: Physics or metaphysics?" in: R. Le Poidevin and M. MacBeath (Eds.) (1993).

Le Poidevin, R. (2000) "Continuants and continuity”, The Monist, 83(3), pp. 381-98.

Le Poidevin, R. (2007) "Image and instant: The pictorial representation of time", in: Le Poidevin, R. The Images of Time (Oxford: Oxford Scholarship Online Monographs).

Le Poidevin, R. and MacBeath, M. (Eds.) (1993) The Philosophy of Time (Oxford: Oxford University Press).

Lessing, G. E. (1969) Laocoön, trans. E. Frothingham (New York: Noonday Press).

Lewis, D. (1983) "Survival and identity", in: Philosophical Papers: Volume 1 (Oxford: Oxford University Press).

Lewis, D. (1986) On the plurality of worlds (Oxford: Blackwell Publishers).

Lewis, D. (1988) "Rearrangement of particles", in: D. Lewis (1999).

Lewis, D. (1999) Papers in metaphysics and epistemology (Cambridge: Cambridge University Press).

Lewis, D. (2002) “Tensing the copula”, Mind, 111, pp. 1-13.

Mellor, D. H. (1998) Real Time II (London: Routledge).

Quine, W. V. O. (1950) "Identity, ostension, and hypostasis", in: W. V. O. Quine (1953).

Quine, W. V. O. (1953) From a Logical Point of View (Cambridge, MA: Harvard University Press).

Russell, B. (1903) Principles of mathematics (Cambridge: Cambridge University Press).

Sider, T. (1997) "Four-dimensionalism", The Philosophical Review, 106, pp. 197-231.

Sider, T. (1999) "Global supervenience and identity across times and worlds", Philosophy and Phenomenological Research, 59, pp. 913-37.

Sider, T. (2000a) "Recent work on identity over time", Philosophical Books, 41, pp. 81-89. 
Sider, T. (2000b) "The stage view and temporary intrinsics", Analysis, 60, pp. 84-88.

Sider, T. (2001) Four-dimensionalism (Gloucestershire: Clarendon Press).

Simons, P (2000a) "How to exist at a time when you have no temporal parts?", The Monist, 83, pp. 419-36.

Simons, P. (2000b) "Continuants and occurrents", Proceedings of the Aristotelian Society, 74, pp. $78-101$.

Shoemaker, S. (1969) "Time without change", Journal of Philosophy, 66(12), pp. 363-81.

Thomson, J. J. (1983) "Parthood and identity across time", The Journal of Philosophy, 80, pp. 201-220.

Van Inwagen, P. (1981) “The doctrine of arbitrary undetached parts”, in: P. Van Inwagen (2001).

Van Inwagen, P. (1990a) Material beings (Ithaca, NY: Cornell University Press).

Van Inwagen, P. (1990b) "Four-dimensional objects", in: P. Van Inwagen (2001).

Van Inwagen, P. (1985) "Plantinga on trans-world identity", in: P. Van Inwagen (2001).

Van Inwagen, P. (2000) "Temporal parts and identity across time", in: P. van Inwagen (2001).

Van Inwagen, P. (2001) Ontology, Identity and Modality (Cambridge: Cambridge University Press).

Walton, K. L. (1984) "On the nature of photographic realism", Critical Inquiry, 11(2), pp. 246-77.

Walton, K. L. (2008) Marvelous Images: On Values and the Arts (Oxford: Oxford University Press). 